\title{
Police Transfers and Job Satisfaction: Case of Nairobi City County, Kenya
}

\author{
Samwel Karanja Ndung'u \\ Department of Security and Correctional science \\ Kenyatta University. \\ Dr. Boniface Muoka \\ Department of International Relations, Conflict and Strategic Studies \\ Kenyatta University
}

\begin{abstract}
Available literature on police transfers and job satisfaction indicate that little is known on whether police transfers affect their job satisfaction. The general objective of the study was to examine the effect of Police Transfers on job satisfaction in the NPS, Kenya. The specific objective was to analyze the influence of criteria used in police transfers on job satisfaction in the National Police Service (NPS). The study was informed by the work adjustment theory. Ex post facto research design was used in this study and the study area was the Nairobi city county. Target population was 8,508 police officers who were working in Nairobi City County by December 2020 of the ranks of senior superintendent, superintendent, assistant superintendent, chief inspector, inspector, senior sergeant, sergeant, corporal and constable. A sample of 382 officers from six sub counties was picked using simple random sampling. Questionnaires and interviews were used to collect the data. Research instruments were pretested in Kiambu county. Questionnaire were administered to respondents in five sub counties of Kasarani, Starehe, Kamukunji, Westlands and Embakasi who were required to respond to the questions in the provided spaces. Interviews were conducted with three senior officers working in the directorates of personnel. Quantitative data was analysed by first finding the percentages for the officers who are very satisfied, satisfied, neutral, dissatisfied or very dissatisfied with their work. Qualitative data was analysed by grouping it into themes, finding patterns and common characteristic and drawing of insights from the observations. Results have been presented in form of tables, graphs and text. It was found that there was no relationship between police transfers and job satisfaction and that transfer criteria does not influence job satisfaction in the police service. Based on the study findings where no relationship between transfers and job satisfaction was found, it is recommended that similar research be conducted to find out if the county(area) of current deployment and nature of duties in the current deployment has any significant effect on the job satisfaction among police officers in the NPS.
\end{abstract}

Keywords: Police Transfers, Criteria, Job Satisfaction, National Police Service, Kenya.

DOI: $10.7176 / \mathrm{PPAR} / 11-5-07$

Publication date:June $30^{\text {th }} 2021$

\subsection{Background to the Study}

Kenya National Police Service Commission (2015), defines transfer as the movement of a police officer from the present working station to a new one and issues concerning the officer including his/her moving of pay point. The transfer of personnel is normal and good to observe in management of employees as it has strong authority on employees' attitudes in workplace.

Although sometimes transfer is accompanied with promotions, mostly it is a lateral change of workforce from one job station to a different one with similar tasks, status, remuneration and perquisite (Dep, 2006). According to Iwamoto (2006), one of the ways to refresh an organization is the frequent transfer of section and department heads every one or two years. Transfers are expected to meet organizational requirements (in technology, volume of production, product line, organization structure), to satisfy various needs of employees (such as to work under friendly superior, to shift to native place, for health reasons, to take up challenging opportunities), to provide multi-skill to the employee, to make suitable adjustment in work force and to punish employees for misconduct (Dep, 2006). Where there is deficit of technical knowhow in one department or area, employees with such skills can be transferred to the department with deficit from another department where such skills are in surplus which in turn impacts positively to production, product line and organization structure. At the same time transfers can be used to meet the convenience of employees by posting them in friendly environments if it does not adversely affect their production or the organization in general.

In a study conducted by Hannay and Chism (1988) in Canada to find out how transfers impact on teachers' proffessional progress, it was found out that senior ranking teachers believed transfer enable them to grow in their careers. Although low ranking teachers did not believe that there is any career development which they can associate with transfer, their supervisors reported that they (low raking teachers) improved after a transfer 
(Hannay \& Chism 1988). There is no harmony therefore from these two cadres as to whether transfers develop employees in their carreers.

Transfers can either originate from management or employees themselves with the institution's authorization. Employees may seek transfers to be where they can be able to get more allowances, or where they can get better working conditions attached to the new position. Other times, employees request for transfers to be able to avoid personal conflicts with workmates, to pursue other opportunities which could not be existing in their current position, due to medical reasons, to join their friends and relatives, or other personal conveniences. Transfers can also be used to place employees where they can be more effective or where they can get more job satisfaction (Singh \& Rawat, 2006). Transfer could therefore be necessary owing to range of reasons.

Job satisfaction concerns the satisfaction with reinforcers found on the job. In theory of work adjustment, satisfaction is the perception of how well environment reignforcers correspond to person's values and needs. According to Dawis (1994) as cited by Shtivelband (2014), satisfaction of employees can be attained through reinforcement of individual's six values; Achievement, Comfort, Status, Safety, Autonomy and Altruism. The six values are believed to better represent other values of job satisfaction. They argue that the reinforcers of the six values can further be clustered into three depending on the values each of them is reinforcing. In the three categories; those reinforcing achievement, and autonomy were classified as a self-reinforcement factor, those reinforcing status and altruism as social reinforcement factor, and those reinforcing safety and comfort as environment reinforcement factor.

A study carried out in German banking and financial services sector by Kampkötter, Harbring, and Sliwka (2018) showed that transfer of employee improved job performance of employees who were performing well prior to their transfer. The study also found out that transfers did not add value to the employees who were not performing prior to their transfers. In a study conducted in health sector in India by Schaaf and Freedman (2013), it was found out that transfers and posting were being done in a manner that neither maximizes the required outcomes nor respect the norms of the profession. In a survey carried out in Parkistan on Effects of Teachers' transfer on school system, it was found that transfer affects individual teacher's performance (Noor, Ishaque, Memon \& Lodhi, 2012). A research done in Turkey by Mair and Tarling (2000) found that no matter what the experiences of the police officers, half of them believe that laid down procedures are not adhered to in either transfers or promotions.

In Nigeria, Isaiah (2012) indicated presence of a correlation between personnel management process and achievement in an Organization. In another study carried out in Amhara Ethiopia by Kebede (2010), unfair transfer and lack of transfer are among the reasons why police officers leave the service. Ekuwam (2014), in a study on job satisfaction among teaching staff, argued that when an employee is overworked, his/her satisfaction may be negatively affected. Being transferred from one station to another may be favorable or unfavorable depending on the magnitude of the workload at the desk either in the previous station or in the new station. If employees feel more secure, they are likely to be more productive. Transferring a person from one station to another (especially without replacing him or her) increases the workload of remaining employees which may stress them up. Similarly, when more personnel are increased in a given area, it gives more relief to officers in the station he/she is reporting. If the organization policy is not promising in job security of the employees, it is likely to affect the employees' output. Employees' efficiency can also be adversely affected if they are denied some independence to exercise their potential or if the status accorded to them is not appealing. Given that the NPS has a transfer Policy, little is known on how adherence or lack of it can be harmful or affect the way the Police officers work.

A survey carried out in 2015 by KNCHR and Centre for Human Rights (University of Nairobi), on the state of police reforms in Kenya established that there are still arbitrary transfers, tribalism, nepotism and harassment of junior officers by their seniors (KNCHR \& Centre for Human Rights-University of Nairobi, 2015). However, the observation was done the same year when the NPSC created Transfer Policy and the study did not factor in the effect of the policy. There have also been further provisions in the Service Standing Orders which was not in effect by then which were also geared towards addressing the challenges associated with police transfers. There is lack of enough information on whether the transfers affect job satisfaction of police officers. A research is therefore necessary to find out how the transfers affect job satisfaction in the NPS, Kenya. Transfer fall within the transfer policy and therefore in is important to evaluate their trend and how it affects job satisfaction needs in the Service.

\subsection{Statement of the Problem}

Strategy on transfer should be designed in a way that guides the management in a standard way of conducting the transfers of its employees. NPSC made transfer policy in the year 2015 and Inspector General (IG) issued the NPS service standing orders in year 2017. The two documents set guidelines and procedure on how transfers in the NPS should be conducted. However, in the end of term report, IPOA reported that the situation remained unchanged as officers kept making allegations/ complaints of biased transfers, with no clear criterion being 
followed on the same (Independent Policing Oversight Authority, 2018).

Transfers in police service are still arbitrary, marred with tribalism, nepotism or sometimes used by senior officers to harass their juniors (KNCHR \& Centre for Human rights and Peace University of Nairobi, 2015). Transfer have been arbitrary, erratic and against the provisions of the written down policies on the same. On a survey carried out by Transparency International in Nairobi and Kisumu Counties in year 2016, Police cited transfers as one of the frustrating aspects in their job (Kenya Transparency International, 2016). Under natural circumstances, the productivity of employees in an organization would be different when subjected to different conditions and thus insinuating their satisfaction equally change with the change of working conditions, level of activity and behavior (Panagiotopoulos \& Karanikola, 2018). There is little empirical knowledge on how transfers affect the police officers' job satisfaction. The impetus that motivates this study is that, there is limited knowledge on whether transfers have an effect on the officers' job satisfaction. The study explored criteria and rates of police transfers and their effect on job satisfaction in NPS.

\subsection{Objective of the Study}

The general objective was to examine the effect of Police Transfers on Job Satisfaction in the NPS, Kenya. The Specific objective of the study was to establish the influence of criteria used in police transfers on job satisfaction in the NPS

\subsection{Research Questions}

How do the criteria used in police transfers affect job satisfaction in the NPS?

\subsection{Significance of the Study}

The research has stretched the frontiers of knowledge on the nexus between transfer and job satisfaction among officers working in the National police Service in Kenya and has availed evidence-based information to NPSC when reviewing the transfer policy by providing insights on whether police transfer affect job satisfaction. The study also provides evidence-based information to the commanders on how the transfer can be applied positively to improve the job satisfaction in NPS. It is also a tool for building knowledge for use by other scholars and researchers on transfers and job satisfaction.

\subsection{Literature Review}

Literature has been reviewed from past studies in relation to transfers and job satisfaction. Little was however found on how the transfer affects Job satisfaction.

\subsubsection{Criteria used in police transfers in the NPS}

Each employee would wish to see himself/herself in a good place or condition. Good policies can avail equal opportunities to all staff (Aziz, 2019). Security sector is labour intensive and therefore investment and proper management of human resource systems and practices has a big stake in the output of the sector. In India Gandhi (2019) found out that the organisations concentrated more on infrastructure of the human resource but did little in finding out if the existing terms and conditions were attractive enough or what employees need to remain in the job.

In a study carried out in Parkistan by Noor, Ishaque, Memon and Lodhi (2012), it was found that transfer affects individual teacher's performance. This was also echoed by Onsumu (2014) who found the transfer compromised the quality of education and sometimes made teachers want to move to other professions. Similar findings were reported by Kenyan Judiciary where a stakeholder's engagement revealed that transfer of judges and magistrates is a significant cause of delayed court proceedings (Judiciary, 2018). Lipsky (1970) on the other hand had earlier found out that transfers enable the management address the cases of adequate supply of labour (particularly skilled labour) to new areas where they are required.

In Kenya, National Institutions have been undergoing transformation since promulgation of new Constitution 2010 and NPS has equally been in continuous reforms. From the recommendation of National Task Force on reforming police service, to the change of Kenya constitution in year 2010 which established NPSC to deal with the Human Resource matters of police officers (transfers and deployment included) and the IPOA to hear the complains against police officers (including those of transfers), NPS has continuously been undergoing transformation aimed at improving its service delivery.

The IG in accordance to the National Police Service Act issued Service Standing Orders which further directs how transfers should be done. According to the Service Standing Orders, an officer can be considered for a transfer after serving in a duty station continuously for not less than one year and not more than three years save for exceptional circumstances where the Commission may disregard the period (National Police Service Standing Orders, 2017). The standing order further provides that the officer being transferred shall be adequately facilitated where applicable.

The transfer regulation and National police service Act also empowers the IG to do deployment of police 
officers in Kenya. According to the regulation, deployment should be for a period of three months but can be extended with the approval of the commission due to the operational requirements as long as it does not exceed one year. In case the deployment exceeds one year, the commission considers transferring the officer. The provision thus shows that a deployment can mutate to being a transfer. The IG can therefore initiate transfer through deployment and extending the period of deployment for the commission to convert the deployment to a transfer.

In their endeavor to know the level of reforms in police service, KNCHR and Centre for Human Rights University of Nairobi (2015) established that there are still arbitrary transfers, tribalism, nepotism and harassment of junior officers by their seniors within NPS. On a survey carried out by Transparency International in Nairobi and Kisumu Counties; promotions, transfers and deployments were mentioned as some of the frustrating aspects in NPS (Transparency International Kenya, 2016). Although some legal framework has been put in place to address the challenges surrounding the police transfers, it is not clear if indeed it has solved the problem.

\subsubsection{Theoretical Framework}

The study was informed by the work adjustment theory. The theory was originally developed by René Dawis, George England and Lloyd Lofquist from the University of Minnesota in 1964. In this theory, when workers' capabilities match with what the organization requires, they have a higher possibility of having good performance and be considered by employers as satisfactory. In a similar way, when rewards (reinforcers) received from the organization matches with the values which the worker seeks to get by working, the worker considers that work to be satisfying. According to the theory, there are six values that workers seek to satisfy: Achievement (situations that inspire success and advancement), Comfort (settings that boost absence of worry and anxiety), Status (setting that provide appreciation and prestige), Altruism (situations that nurture harmony and service to others), Safety (conditions that establish predictability and stability) and Autonomy (conditions that increase personal control and creativity) (Winter, 2009). Dawis et al (1987) as quoted by Shtivelband (2014), further reduces these values into three; self (internal), social (other people) and Environment (External). The theory assumes that all individuals endeavor to get and sustain a good match with the environment. Most of the problems at work (like choosing profession, to remain or to quit a job, good or poor performance at work, and getting satisfied or not satisfied with the job) can be well explained by lack of perfect match between the workers' requirement and organisations' requirement.

Employees spend considerable amount of their time at work thus making it the environment which they relate to most of their time. Satisfactory worker is one who meets the requirements of work environment, while a satisfied worker is one whose requirements (values) are met by work environment. Satisfactoriness and satisfaction are indications of a worthy correspondence between an individual and job setting (Dawis, Lofquist, \& Weiss, 1968). Transfers could be geareared towards meeting the requirements of an mployee or the requirements of the organisation. It therefore follows that they can make an employee a satisfactory worker or a satisfied worker depending on the extent to which they address the needs of the employee and how that matches with the needs of the organisation.

The individuals bring some capabilities to the work environment. The work environment provides some rewards like salary, status and social relations to the worker. The capabilities which workers possess enable them to meet requirements of work environment. Rewards provided by work environment on the other hand makes it able to meet the workers' desires. Work environment and individual are considered to be correspondent if each meets the requirement of the other. At work, correspondence can be expressed as fulfilment of environment requirements by the employees and fulfilment of the employees' requirement by the environment (Dawis, et al 1968).

Police service is the environment where Police Officers relate with in the course of their job. From the perspective of the theory adopted in the study, Police Officers offer their skills to satisfy the environment (Police Service) and they expect reward from the environment to be satisfied. If the Police Service fulfills the requirement of the officers, then the officers will be satisfied police officers and when the police officer satisfies the requirements of the police service, they are satisfactory police officers. The Policies in the Police Service and how they are implemented should therefore be geared towards fulfilling the requirements of the police officers and the service and skills that police officer offers to the Police Service should be geared towards fulfilling the requirements of the Police Service for there to be correspondence.

\subsection{Research Methodology}

Ex post facto design was used in this research. The design is used when the variation of interest has already been determined in the natural course of events. It involves looking at something that has happened in the past and establish whether a relationship of the variables at play can be determined. The design involves no direct manipulation of the independent variable as it assumes the cause has already occurred. It is therefore used when the researcher does not have control over the selection and manipulation of the independent variable. In this 
study, Ex post facto design was appropriate since the researcher had no control over transfers as they had already happened and the frequency of the same could also not be manipulated.

The research was conducted in Nairobi City County, Kenya. Nairobi City County is the Capital City of Kenya and is the second smallest county in size (geographical area) from Mombasa with an urban setting and a population of 4,397,073 according to 2019 census. The County has a total area of $696.1 \mathrm{Km}^{2}$ and is located between longitudes $36^{\circ} 45^{\prime}$ East and latitudes $1^{\circ} 18^{\prime}$ 'South. It lies at an altitude of 1,798 meters above sea level. It is the city and county with the largest population in Kenya and is very ethnically diverse. Officers serving in the county are from APS, KPS and the DCI. The county was chosen because unlike the other forty-six (46) counties, it had a bigger number of APS and DCI personnel.

The target was all the NPS officers in the cadres of SSP, SP, ASP, CIP, IP, S/SGT, SGT, CPL and (A)PC working in Nairobi City County. Officers above the rank of SSP were excluded because mostly they are more of implementers than subjects of transfer. The population within Nairobi City County was chosen because unlike other counties which have very few APS and DCI staff, the county has higher number of personnel from the two. The population was therefore more representative of NPS than that of other counties.

Six sub-counties were sampled within Nairobi City County. The formula provided by Ryan (2013) was used to copute sample size. A sample was then randomly picked from each service and the directorate in the ratio of their numbers in the NPS. The study assumed an error of $5 \%$.

Random sampling was used in selecting the respondents of questionnaire. It was chosen because it ensured the sample fairly represented police officers in the county while taking cognizance of their various characteristics in terms of rank, length of period served and age. The method also gave all officers an equal chance of being selected in the sample. The population was first categorized in to KPS, APS and DCI. The researcher then chose the sample size per rank and service/directorate in proportion to their population. In situations where the proportion was very low, the researcher ensured there was at least one officers selected from each rank and service.

Questionnaires were used to collect the data. Questionnaire refers to a set of predetermined questions used to collect the data. Questionnaires were used because they could enable the researcher have a wide coverage of respondent within a short time and at minimal costs. The uniformity of questionnaires also enabled the researcher to be consistent on the information being sought from the respondent. The questionnaire was useful in collecting both qualitative and quantitative data. Minnesota Satisfaction Questionnaire (MSQ) was adopted to collect data. MSQ is more specific about the issues which employees consider as addressing job satisfaction than other more general measures of job satisfaction. MSQ was made to ascertain the level of satisfaction member of staff have on their jobs. MSQ exists in three forms: two lengthy types (1977 and 1967 versions), and a short form which contains 20 items that best represent each of the 20 scales in the long version. The latter was used in this study. However, the Questionnaire was improved to capture the aspects of transfer. The researcher also had interviews with three senior officers in the directorate of personnel and human capital in the KPS, APS and DCIs to get more qualitative data. Each service and DCI have one directorate of either human capital or personnel and it was believed that having a representative from each of the three would give the perspective of the implementers of transfers.

To ascertain reliability of my questionnaire, test-retest method was applied. The same questionnaire was administered twice in an interval of two weeks to a section of the police officers to find out if they were consistent in the answers they gave. The researcher found a correlation coefficient of more than +0.7 between the results obtained in the first and the second time, the instrument was thus assumed to be reliable.

The data was cleaned and coded to make it easier to analyze quantitatively by use of computers. The data was then fed into the Statistical Package for the Social Sciences (SPSS) version 23 for windows for purposes of analysis and reporting. The study data was analyzed using descriptive statistics to establish trends and patterns.

\subsection{Findings and Discussions}

This chapter presents the organization, analysis, presentation and discussion of data.

\subsubsection{Demographic information}

Out of the total number of respondents, $76 \%$ were male while $24 \%$ were female. The results show that police service is a male dominated field. Majority of them (49\%) were in the age bracket of between 31 and 40 years. The age bracket of between 41 and 50 years were the second biggest number at $19 \%$ followed closely by the age bracket of between 21 and 30 years at $18 \%$. Those above 50 years' bracket were $14 \%$ while there was no respondent below 20 years. Among the respondents, the rank with the highest number of respondents was (A)PC at $58 \%$ followed by CPL at 19\%. The ranks of SGT, S/SGT IP, CIP, ASP, SP and SSP were $6 \%, 1 \%, 8 \%, 4 \%$, $1 \%, 1 \%$ and $3 \%$ respectively. Most of the respondents had secondary level of education $58 \%$ followed by those with bachelor's degree at 21\%. Diploma holders were 20\%, Post graduate degree holders were 5\% while there was no respondent with only primary level of education. There were $74 \%$ of the officers who had served for three years or less in their station, while $13 \%$ had served 4 to 5 years, $7 \%$ had more than 10 years, $5 \%$ had 6 to 8 
years and $2 \%$ had 9 to 10 years in their station at the time of this study.

The gender proportion may be due to their proportion at the time of recruitment where the number of males has been historically higher than that of females. Most of the officer were at a middle age of between 31 and 40 years of age. This could have been as a result of the massive recruitment from year 2013 in fulfilment of the Jubilee government manifesto of increasing the police-citizen ratio from 1:1150 to a ratio of 1:800 citizens within five years by recruiting an extra 15,000 police officers per annum. Although the recruitment was not 15000 per annum as envisaged in the manifesto, there were four recruitments of 10000 officers each in the said period. Officers with the 11-20 years lenghth service were the majority at (44.6\%) folloed by those with above 20 years at $(29 \%), 6-10$ years $(15.1 \%)$ and below 5 Years. Officers in KPS were the majority $(46.8 \%)$ followed by APS (40.3\%), DCI (11.8\%) and AIU at (1.1\%). This can be well explained by the proportion of their numbers in NPS. Most of the respondents were constables because the structure of the police service constable is usually lowest rank in the hierarchy and their number is usually higher. The numbers shrink as you ascend up the ranks. However, depending on deployment, proportion of officers of a particular rank may be more or few in one station than expected. Majority of the officers had secondary level of education. This could be because during recruitment, the basic entry requirement is secondary level of education with very few graduates being recruited occasionally. Some officers have however continued with education while still in service thus uplifting the level of education in the Service. Most of the officers said they had stayed 0 to 3 years in their current station. This indicates many of them had stayed three years or less in their current station.

Transfers within 15 years

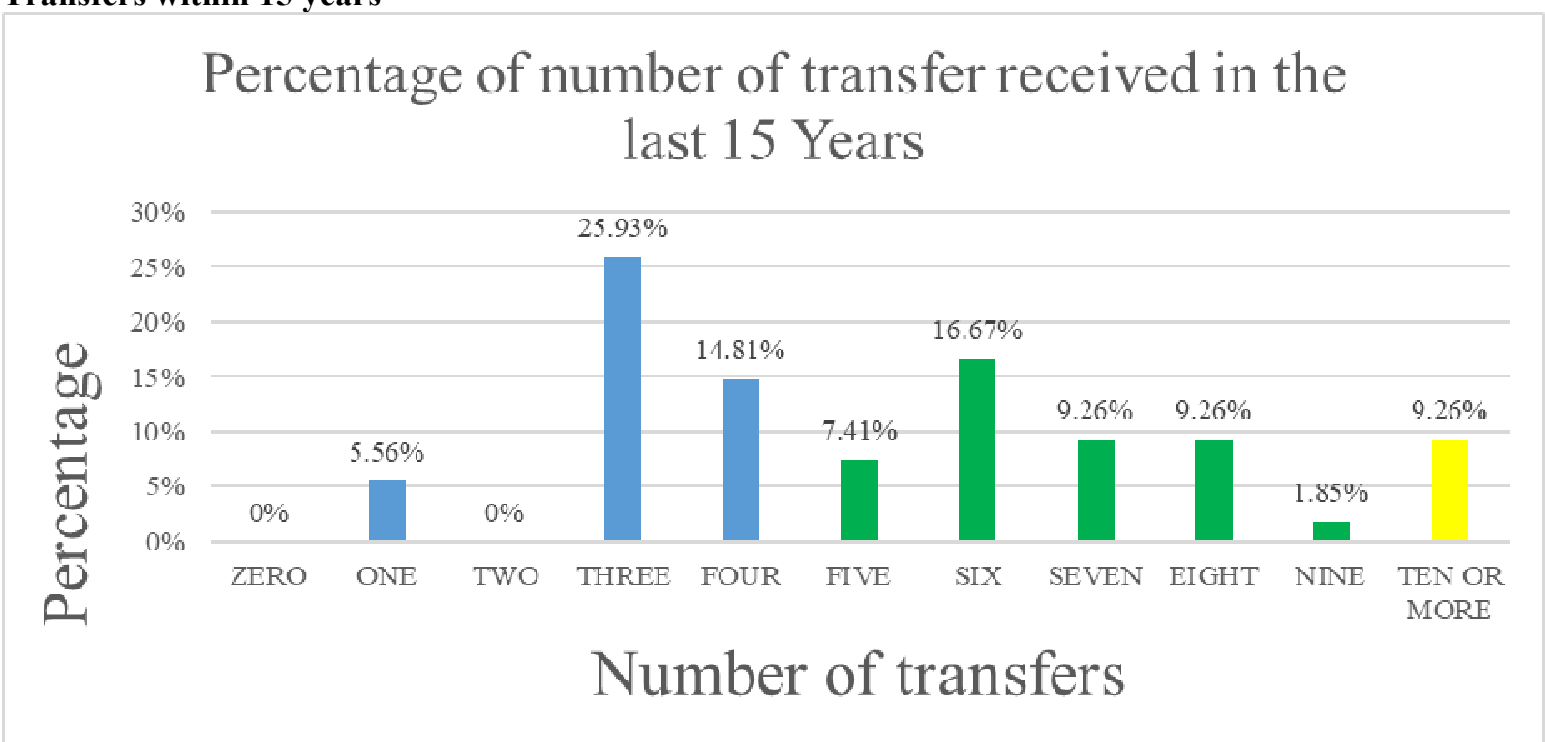

Figure 1. Percentage of number of transfer received in the last 15 Years

In the category of officers who had worked for more than twenty years, the highest percentage $(25.93 \%)$ of officers were those who had been subjected to three transfers within a window period of 15 years. This imply they were on average taking about five years before being transferred to a new station. There were $46.3 \%$ of the respondent who reported to have received four transfers or less thus indicating they were on average taking longer than three years in one station before being transferred. The officers had also suggested that they would wish to see the transfer regulations being implemented thus showing there was a perception that the regulations were not being implemented as provided.

One of the officers suggested "If the NPS policies are followed to the letter including the career progression guideline and S.S O guidelines on transfer, officers would have confidence in the Service Human resource."

The findings show transfer regulation on the time period required before one is moved to a new station was far from being achieved. Failure to follow the laid down guidelines could also be the reason that most of the officers reported that they were dissatisfied with the way the transfers were being carried out in the NPS. 
Transfers within 10 years

\section{Percentage of number of transfer received in the last 10 Years}

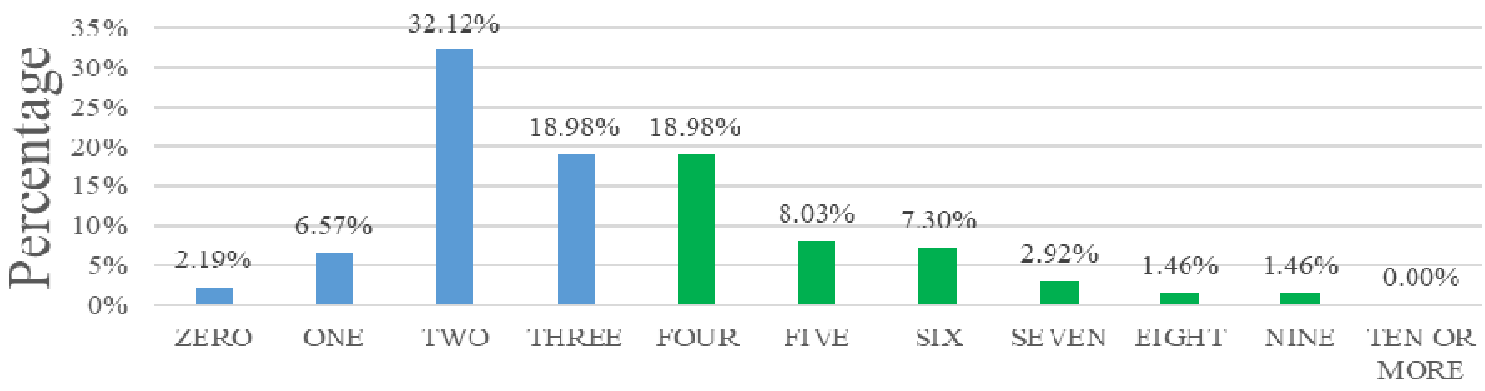

\section{Number of transfers}

Figure 2. Percentage of number of transfer received in the last 10 Years

It was observed that for most of the officers who have worked for eleven (11) years and above, 32.12\% (highest percentage) said they have been subjected to two transfers within a window period of 10 years implying they were on average taking about five years before being transferred to a new station. About 59.56\% indicated that they had received three transfer or less. This implies that were on average taking more than three-year period in one station before being transferred to a new station. This shows that many of the officers were staying longer in one station than the stipulated three-year maximum period one is expected to stay in one station before being transferred. Some respondents had indicated that they would wish to see the transfer regulation being fully implemented. The interview with the human resource officers had shown that having a one year and a maximum of three-year period before one is transferred is not attainable. One officer from the directorate of personnel suggested that minimum period before one is transferred be revised to three years. The senior officers argued that the current budget allocations would not be enough in paying the officers transfer allowance in case the provisions in the regulations were to be faithfully followed.

Interviewee 2 said "Many transfers mean more transfer and baggage allowance. Where would we be getting funds from if we keep transferring people every other day? We have a lean budget and we would not want to subject our officers to suffering. Even as we talk, we have pending transfer allowance which have not been paid yet the officers have already proceeded for transfers."

Another argument which came from the implementers of transfer is that one-year minimum period required before effecting a transfer is too short for an officer to have well understood crime dynamics in their area of duty. They claimed that the residents would also not have reaped optimally from the experience the officers might have gained in understanding their area of duty.

From the findings, it can be seen that in practice, the average period before one is transferred to a new station is about five years. This indicates that the provisions in the regulation and SSO on the period an officer should serve in one station before being transferred is not being followed. The deviation from the legal provisions on transfers could be attributed to the operational difficulty in the nature of police work and the lack of funds to facilitate officers during transfers. This however does not go well with the officers as some suggested that they would wish to see the regulation being followed. From the police management point of view, officers' productivity is maximized when they are well oriented in their area of operation to understand crime trends and how they occur. It would therefore not optimize the police performance in general if officers are transferred within intervals of short period like one year and the benefits which would have otherwise been realized by longer stay would be lost.

Interviewee 1 said "The time period of stay in one station is not operationally practical in police work. The three years prescribed in the regulation as the maximum time to stay in one station for example may not be enough for the officer to have utilized the experienced gained at that station in understanding the crime trend of the area. If you keenly observe those legal provisions, they are just meant to make work difficult. The provisions on transfer need to be revised. They should also involve us when making those regulations, we understand the police work better. When you are not in Police Service, you may not well know the challenges we face in making those regulations work."

It can be observed from the results that transfer guidelines are not being implemented and that is contrary to the expectations of the officers. At the same time, the management feels that the guidelines in their current state are not workable in the NPS. The results show there could be a need to harmonize the way transfers are 
conducted in NPS and what is legally provided on the same.

Transfers within 5 years

\section{Percentage of number of transfer received in the last 5 Years}

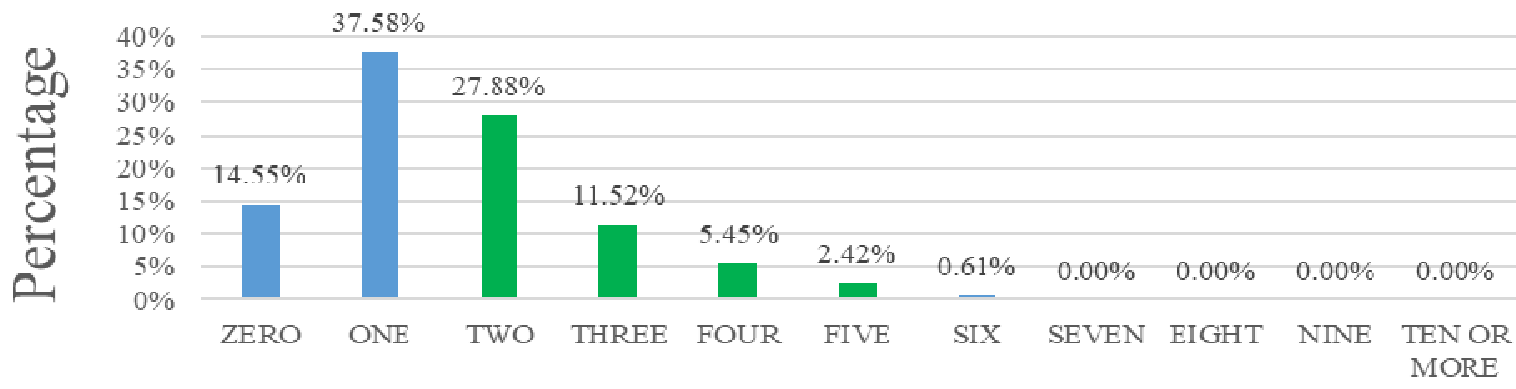

\section{Number of transfers}

Figure 3. Percentage of number of transfers received in the last 5 Years

Among the officers who have worked for six (6) years and above $37.58 \%$ (highest percentage) said they had been subjected to one transfer within a window period of five years thus implying that on average, they were taking five years or less before being transferred to a new station. About 52.13\% of the officers received one transfers or none within the five years' period thus indicating they were taking about five years or more in one station before being transferred a different station. A small percentage $(0.61 \%)$ of the officers had been subjected to six transfers within the same window period thus implying they were on average taking less than one year before being transferred to a new station. There was no officer subjected to seven or more transfers within the five-year window period. It can therefore be observed that the minimum one-year interval period between transfers was being followed. However, similar adherence to the maximum three-year interval period between transfers was not being followed. Interview with the senior personnel officers had shown that having a one year and a maximum of three-year period before one is transferred is not attainable.

The senior officers argued that the current budget allocations would not be enough in paying the officers transfer allowance in case the provisions in the regulations were to be faithfully followed. Another argument which came from the implementers of transfer is that one-year minimum period required before effecting a transfer is too short for an officer to have well understood crime dynamics in their area of duty. They claimed that the residents would not have reaped optimally from the experience the officers might have gained in understanding their area of duty.

From the findings, it can be seen that in practice, the average period before one is transferred to a new station is about five years. This deviates from what is provided for in the regulations and SSO of a maximum three-year interval period between transfers. It is however worth noting that more than $99 \%$ of the transfer complied with the minimum one-year interval requirement as provided for in transfer regulations and SSO. The deviation from the legal provisions on transfers could be attributed to the operational difficulty in the nature of police work and the lack of funds to facilitate officers during transfers. This however does not go well with the officers as some suggested that they would wish to see the regulation being followed. From the police management point of view, officers' productivity is maximized when they are well oriented in their area of operation to understand crime trends and how they occur. It would therefore not optimize the police performance in general if officers are transferred within intervals of short period like one year and the benefits which would have otherwise been realized by longer stay would be lost. 
Transfers within 3 years

\section{Percentage of number of transfer received in the last 3 Years}

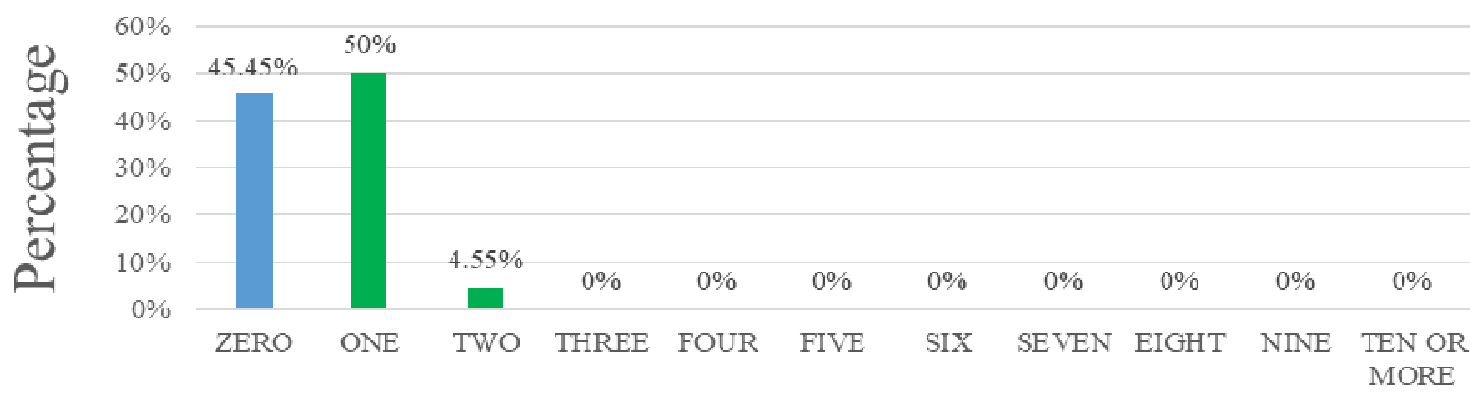

\section{Number of transfers}

Figure 4. Percentage of number of transfers received in the last 3 Years

Most of the officers $95.5 \%$ have received one or no transfer within three years. Only $4.45 \%$ of the officers had received two transfers within the three-year window period. It can therefore be observed that the minimum one-year interval period between transfers was largely being followed. Adherence to the maximum three-year interval period between transfers could not be observable since some respondents had not served beyond the three years. Interview with the senior personnel officers had shown that having a minimum of one year and a maximum of three-year period before one is transferred is not attainable. This could be because of the reasons given by the commanders of maintaining an officer in one station for a longer period. Although it was evident that minimum of one year in a station has been observed, the three-year maximum stay in one station could not be assessed.

\subsubsection{Influence of Criteria Used in Police Transfers on Job Satisfaction in NPS}

On the criteria used in police transfers, the responses were ranked in a Likert scale. The response of strongly disagree was ranked as 1 , disagree as 2 , neutral as 3 , agree as 4 and strongly agree as 5 . The Likert scale was compressed to three scales where those who answered strongly agree were summed up with those who answered agree and those who answered strongly disagree were summed up with those who answered disagree. For every question, a percentage of respondent who gave each of the scale was computed. The percentages were as shown in table 1 .

Table 1: Criteria Used for Transfers

\begin{tabular}{|c|c|c|c|c|}
\hline & & & al & ee \\
\hline 1 & $\begin{array}{l}\text { I understand the criteria used when transferring police officer in the } \\
\text { National Police Service }\end{array}$ & 58.06 & $20.97 \%$ & 97 \\
\hline 2 & The National Police Service has a Transfer Regulation & $43.55 \%$ & $21.51 \%$ & $4.95 \%$ \\
\hline a & Service considers the years served in a station before & 70.4 & $3.98 \%$ & $15.59 \%$ \\
\hline 4 & ition, he/she must have & $66.67 \%$ & 0 & $Y_{0}$ \\
\hline 5 & years in one station, you are transferred to & $64.52 \%$ & $16.67 \%$ & $18.82 \%$ \\
\hline 6 & 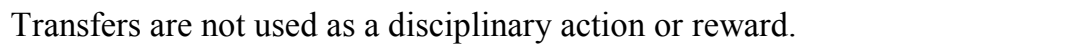 & 62.5 & $15.59 \%$ & $21.51 \%$ \\
\hline 7 & al Police Service considers ethnic & $63.44 \%$ & 0 & $12.90 \%$ \\
\hline 0 & re adequately facilitated. & & & \\
\hline 9 & $\begin{array}{l}\text { pt the operations of the concerned } \\
\text { pt on necessity and are carried }\end{array}$ & & $17.20 \%$ & $13 \%$ \\
\hline 10 & no Lobbying or canvassing for transfers in the National Police & $63.44 \%$ & $20.97 \%$ & 15.5 \\
\hline & & & & \\
\hline 12 & Am satisfied on the way transfers are conducted in National Police Servic & & $3 \%$ & $13.44 \%$ \\
\hline
\end{tabular}

Source: Researcher, 2021

Majority of the respondents $(58.06 \%)$ indicated that they did not understand the transfer criteria being used 
in NPS while $43.55 \%$ did not agree that NPS has a transfer regulation. A large percentage of the respondents $(70.43 \%)$ disagreed that NPS considers the length of time one has served in a given station before being transferred while $66.67 \%$ also disagreed that officers take at least one year before being transferred to a different station. Most of the respondent (64.52\%) also disagreed that one is usually transferred after serving in one station for a period of three years while $62.90 \%$ disagreed that transfers are not used as a disciplinary action or reward. On ethnic balance and gender representation, 63.44\% disagreed that it's a consideration during police transfers and $80.11 \%$ disagreed that officers are adequately facilitated during transfers. It was not agreeable to majority of the respondents $(66.67 \%)$ that NPS transfers are based on necessity and neither did they agree that there is no lobbying of transfer $(63.44 \%)$ in NPS. A large percentage $(71.51 \%)$ also disagreed with the statement that transfers in NPS are fair and just and $66.13 \%$ did not agree as being satisfied with the way transfers are conducted in NPS.

The statement which received the highest level of objection at $80.11 \%$ was that during transfers, officers are adequately facilitated. An interview with the management had indicated that there are sometimes delays in payment of transfer allowance which are usually due to budget constraint. The statement which was second in the level at it was objected was that transfers are fair and just with $71.51 \%$ disagreeing with it. This was closely followed by the statement that NPS considers the years served in a station before being transferred at $70.43 \%$.

The questions in this section had been derived from provisions of the National Police Service Transfer Regulation and the National Police Service Standing Orders. It was evident from the responses that majority of the officers did not agree existence of the any policy on transfers in NPS and the few who know existence of such policies did not believe the provisions therein were being followed. When asked their opinion on the matters of transfer in NPS, officers lamented on same problems that the regulation was supposed to cure like the odd timings of transfer, failure to consider the officers needs and welfare, use of transfers as a punishment and humiliation, lobbying of transfers, lack of transparency in transfers, ethnicity on transfers, overstay for officers posted in hardship areas, failure to implement transfer policies on transfer, delayed transfer allowance, protection of some officers by their commanders not to be transferred, failure to consider officers with health problem and disabilities during transfers, bribery and corruption, failure to involve junior officers in development of the transfer policies and discrimination during transfers.

It was evident from the responses that police officers did not have a good feeling on the way transfers were being conducted in the NPS. The situation is adversely affecting the attitude of the officers towards their seniors. Failure to follow the existing policies was making the officers to lose faith on NPS like reported by one of the respondents when he said "If the NPS policies are followed to the letter including the career progression guideline and S.S O guidelines on transfer, officers would have confidence in the Service Human resource".

From the interviews with the senior officers (implementers of the transfers), bureaucracy introduced by the transfer regulation and SSO is not practicable in Police administration. They argued that commanders sometimes require rapid fixing of security situations and at times situations may get out of hand as they wait for the National Police Service Commission to implement transfers.

Interviewee 1 said "Application of the regulation may not be possible at times. The nature of duty and expected speed of execution may not allow us accommodate the long process of transfers as prescribed in the regulations"

The human resource officers further argued that although the national police service commission has constitution mandate to determine transfers, the mandate should not interfere with the inspector general's mandate on exercising independent command over the National Police Service as provided by the constitution. Police service is a labour intensive industry and the output is highly dependent on how the labour force is organized and motivated. Limiting the authority of the IG on any of the human resource management aspects dilutes his control over the officers yet the performance of his office is tied to that of the troops under his command. Since the inspector general job is well elaborated by law (including exercising independent command over the National Police Service), commensurate powers should also be vested in that office to enable the office holder perform the functions of the office. Among the necessary powers that the IG should have is that of determining the transfers, promotion and discipline in the Police Service. It would be difficult to rate his/her performance if such powers are not under his/her control. Though most of the senior commanders felt the power of conducting transfer should be in the office of the IG, one of them noted that earlier experiences had shown the powers can be misused. The officer suggested that the power to transfer can be with the IG but there should be an oversight body to audit how those transfers are conducted.

Interviewee 3 said "Transfers should however not be used as a punishment. It's good to have an external body to regulate transfers; in some earlier days it was misused by some commanders by using it to address discipline issues. But there is also a problem to vest the commission with the human resource management aspect of NPS. Police service is labour intensive industry and if the head of the organization cannot be free to organize his personnel in a manner he deems fit, it would be difficult to measure his performance. The current provisions have greatly diluted the grip and command of the IG 
over his officers. It's unfair to deny the IG the control over his officers yet his performance is judged from their performance. Transfer is an administrative issue and should be left on the hands of the IG."

Although the respondents did not appear contented with the way transfers were being conducted and the policies in place in relation to transfer, that did not appear to be having a correlation with the job satisfaction. It can therefore be argued that police officers dislike the way the affairs of transfer are conducted in NPS but that did not have an influence on their job satisfaction as there was very weak correlation between the two.

It appears the perspective of the junior police officers and that of the management in regard to transfer are very different. Junior officers suggest that the regulations need to be followed while the management suggest revision of the transfer policies to reflect the practicable state. This could be due to wide communication gap between senior and junior officers in the Service where the reasons for non-compliant with the policies might not have been communicated to the officers. Lack of wide consultation with the stakeholders could have resulted to a situation where either the views of the junior officers or those of the management were not taken in to account when developing the policies.

From the findings of the study, police administration does not implement what is provided for in the NPS transfer regulations and SSO in regards to transfer. Police service is a complex career and officers are expected by the oath of office to serve impartially in any part of the country and to accept all lawful orders (including transfer order) as may be given from time to time. The mismatch between the legal provisions and the actual practice in relation to transfers could therefore be as a result of the noncompliance of the implementers or from the non-practicability of the regulation as a result of complexity of police career.

The transfer regulations, just like many other regulations and legislations guiding the police service in Kenya in the present day were made few years after the 2007/2008 post-election violence where police were adversely mentioned in some reports of investigation over the violence. The laws and regulations done around that period might have over amplified the suggestions of civil societies which might not be practical in a discipline service. From the human resource point of view, the NPS might also not be doing enough to address the perennial complains about transfers.

The results were consistent with earlier study which had been conducted by Independent Policing Oversight Authority (2018) who reported that officers keep making allegations/ complaints of biased transfers, with no clear criterion being followed on the same. Similar findings were also reported by KNCHR \& Centre for Human Rights University of Nairobi (2015) who found that transfers in police service are still arbitrary, marred with tribalism, nepotism or sometimes used by senior officers to harass their juniors.

Table 1: Satisfaction Questionnaire Analysis

\begin{tabular}{|c|c|c|c|c|c|c|}
\hline & & Mean & $\begin{array}{l}\text { Standard } \\
\text { Deviation }\end{array}$ & Dissatisfied & Neutral & Satisfied \\
\hline 1 & Being able to keep busy all the time & 3.64 & 1.04 & $16.13 \%$ & $15.05 \%$ & $68.82 \%$ \\
\hline 2 & The chance to work alone on the job & 3.11 & 1.11 & $31.18 \%$ & $24.73 \%$ & $44.09 \%$ \\
\hline 3 & $\begin{array}{l}\text { The chance to do different things from time } \\
\text { to time }\end{array}$ & 3.49 & 1.16 & $21.51 \%$ & $19.35 \%$ & $59.14 \%$ \\
\hline 4 & $\begin{array}{l}\text { The chance to be "somebody" in the } \\
\text { community }\end{array}$ & 3.86 & 1.20 & $15.05 \%$ & $12.90 \%$ & $72.04 \%$ \\
\hline 5 & The way my boss handles his/her workers & 3.47 & 1.19 & $20.43 \%$ & $21.51 \%$ & $58.06 \%$ \\
\hline 6 & $\begin{array}{l}\text { The competence of my supervisor in making } \\
\text { decisions }\end{array}$ & 3.54 & 1.15 & $21.51 \%$ & $16.13 \%$ & $62.37 \%$ \\
\hline 7 & $\begin{array}{l}\text { Being able to do things that don't go against } \\
\text { my conscience }\end{array}$ & 3.56 & 1.08 & $16.67 \%$ & $27.96 \%$ & $55.38 \%$ \\
\hline 8 & $\begin{array}{l}\text { The way my job provides for steady } \\
\text { employment. }\end{array}$ & 3.73 & 0.95 & $13.44 \%$ & $13.98 \%$ & $72.58 \%$ \\
\hline 9 & The chance to do things for other people & 3.76 & 1.07 & $14.52 \%$ & $13.98 \%$ & $71.51 \%$ \\
\hline 10 & The chance to tell people what to do & 3.72 & 0.96 & $11.83 \%$ & $20.97 \%$ & $67.20 \%$ \\
\hline 11 & $\begin{array}{l}\text { The chance to do something that makes use } \\
\text { of my abilities }\end{array}$ & 3.67 & 1.15 & $18.82 \%$ & $15.59 \%$ & $65.59 \%$ \\
\hline 12 & $\begin{array}{l}\text { The way National Police Service policies } \\
\text { are put into practice }\end{array}$ & 2.73 & 1.25 & $47.31 \%$ & $20.97 \%$ & $31.72 \%$ \\
\hline 13 & My pay and the amount of work I do & 2.34 & 1.16 & $59.68 \%$ & $20.97 \%$ & $19.35 \%$ \\
\hline 14 & The chances for advancement on this job & 2.69 & 1.20 & $43.55 \%$ & $26.88 \%$ & $29.57 \%$ \\
\hline 15 & The freedom to use my own judgment & 2.94 & 1.20 & $35.48 \%$ & $26.88 \%$ & $37.63 \%$ \\
\hline 16 & $\begin{array}{l}\text { The chance to try my own methods of doing } \\
\text { the job }\end{array}$ & 2.96 & 1.16 & $35.48 \%$ & $27.42 \%$ & $37.10 \%$ \\
\hline 17 & The working conditions & 2.63 & 1.19 & $47.31 \%$ & $23.66 \%$ & $29.03 \%$ \\
\hline
\end{tabular}




\begin{tabular}{|c|c|c|c|c|c|c|}
\hline & & Mean & $\begin{array}{l}\text { Standard } \\
\text { Deviation }\end{array}$ & Dissatisfied & Neutral & Satisfied \\
\hline 18 & $\begin{array}{l}\text { The way my co-workers get along with each } \\
\text { other }\end{array}$ & 3.33 & 1.07 & $22.58 \%$ & $24.19 \%$ & $53.23 \%$ \\
\hline \multirow{3}{*}{$\begin{array}{l}19 \\
20\end{array}$} & The praise I get for doing a good job & 2.91 & 1.28 & $40.32 \%$ & $22.04 \%$ & $37.63 \%$ \\
\hline & $\begin{array}{l}\text { The feeling of accomplishment I get from } \\
\text { the job }\end{array}$ & 3.23 & 1.19 & $25.81 \%$ & $24.19 \%$ & $50 \%$ \\
\hline & Average & 3.64 & 1.04 & $16.13 \%$ & $15.05 \%$ & $68.82 \%$ \\
\hline
\end{tabular}

Source: Researcher, 2021

A mean and standard deviation of the scales was computed for each question. The Likert scale was compressed from five ranks to three ranks. This was done by summing up the respondents who had answered very dissatisfied with those who had answered dissatisfied and placing the two under the rank of dissatisfied. Similar summation was done for the respondents who had answered very satisfied with those who had answered satisfied and placing them under the rank of satisfied. Percentages were then calculated for each scale in all the questions.

The statement which had the highest mean was that which suggested that officers have the chance to be "somebody" in the community with a mean of 3.86. It was reinforced by the high percentage $(72.04 \%)$ of officers who had indicated that they were satisfied with provisions in the statement. However, the statement which registered the highest percentage of satisfied officers was that which suggested the police work provided steady employment with $72.58 \%$. The mean for that statement was also not only reasonably high at 3.73 but also had the least standard deviation at 0.95 . Other statement which registered high percentage of satisfied officers were; the chance to do things for other people $(71.51 \%)$, being able to keep busy all the time $(68.82 \%)$ and the chance to tell people what to do $(67.20 \%)$. The mean under of Likert scale values in these statements were also reasonably high at $3.76,3.64$ and 3.72 respectively while standard deviation remained reasonably low at 1.07 , 1.04 and 0.96 respectively.

It was observed that the mean in most of the questions was above 3 (neutral) which shows they were leaning towards the state of being satisfied. There were few questions however whose average showed a mean of less than 3 thus indicating that majority of respondents on those questions leaned toward being dissatisfied. The "pay and the amount of work I do" had the least mean (2.34) showing that pay is the element which the respondents indicated to be very dissatisfied about. The dissatisfaction with the pay was also confirmed by the highest percentage of the respondents (59.68\%) indicating they were dissatisfied with the match between the pay and the amount of work they do. Others statements which had a mean of less than three and thus registering a level of dissatisfaction include; "the working conditions" with a mean of 2.63, "The chances for advancement on the job" with mean of 2.69, "the way National Police Service policies are put into practice" with a mean of 2.73 , "praise got for doing a good job" the with a mean of 2.91, "the freedom to use my own judgment" at mean of 2.94 , and "the chance to try own methods of doing the job" with a mean of 2.96 .

The results indicate that the officers registered satisfaction in almost all the questions suggested in the satisfaction part of the questionnaire. On average the mean of all the questions was 3.64 which was leaning towards satisfied. The average percentage of being satisfied was also highest at $68.82 \%$. This indicates that the officers were satisfied with their job. However, the officers had also indicated dissatisfaction with police transfer. Although officers were not satisfied with the transfer, no evidence was found that transfer has any influence on job satisfaction.

Although the officers were dissatisfied with the way transfer were being conducted in police service, they remained satisfied with the job. This deviated from the results of an earlier study by Singh and Rawat in New Delhi (2006) who had found that transfers can be used to place employees where they can get more job satisfaction. The results of this study also deviated from those of an earlier study carried out in Amhara Ethiopia by Kebede (2010) which found that unfair transfer and lack of transfer to be among the reasons why police officers leave the service. Though the police appeared to be dissatisfied with the way transfers are handled in police organization, they remained satisfied with their job and may therefore transfers may not be a reason for them to leave the service.

\subsection{Conclusion}

It is concluded that transfers do not influence job satisfaction. This was deduced by comparing the responses on the transfers and those of job satisfaction. Although the respondents expressed their dissatisfaction with police transfers, they were satisfied with their job. This implied the transfer did not influence the officers job satisfaction. 


\subsection{Recommendation}

Based on thew study findings and conclusion where it was revealed that there was no relationship between transfers and job satisfaction, similar research should be conducted to find out if the county(area) of current deployment and nature of duties in the current deployment has an effect on the job satisfaction.

\section{References}

Agbozo, G.K., Owusu, I.S., Hoedoafia, M.A. \& Atakorah, Y.B. (2017). The Effect of Work Environment on Job Satisfaction: Evidence from the Banking Sector in Ghana. Journal of Human Resource Management, 12-18.

Aziz, M. T. (2019). An Evaluation of the Employees' Satisfaction of Sonali Bank Limited: A Study on Green Road Branch, Dhaka. Dhaka: Unpublished MBA Report from Daffodil International University.

Chandrasekar, K. (2011). Workplace Environment and its Impact on Organisational Performance in Public Sector Organisations. International Journal of Enterprise Computing and Business Systems, Vol.1(Issue 1).

Constitution of Kenya, 2010. (n.d.).

Publishers .

Eggerth, D. E. (2008). From Theory of Work Adjustment to Person-Environment Correspondence Counseling: Vocational Psychology as Positive Psychology. JOURNAL OF CAREER ASSESSMENT, Vol. 16 No. 1 , February, Vol. 16 No. 1, 60-74.

Ekuwam, I. S. (2014). Determinants of Job Satisfaction among Teachers in Public Primary Schools in Turkana West Sub County, Turkana County. Unpublished Research Project Submitted in Partial Fulfillment of the Requirements for the Award of the Degree of Master of Education of the University of Nairobi.

Gandhi, N. (2019). A Study of Human Resource Policies for Primary Health Care System. Journal of Current Science.

Guntert, S. T. (2015, June 1st ). The impact of work design, autonomy support, and strategy on employee outcomes: A differentiated perspective on self-determination at work. Springer Science+Business Media New York, pp. 74-87.

Hannay, L \& Chism, N . (1988). The Potential of Teacher Transfer in Fostering Proffessional Development. Journal of Curriculumn and Supervision, 122-135.

Harmania, H.M. \& Nessa, H.C. (2016). Exploring the Effect of Staff Achievement on Job Satisfaction in Hong Kong Residential Clubhouse. Journal of Tourism \& Hospitality, 2167-0269.

Hsu, H. Chen, H., Yu, H., \& Lou, J. (2010). Job Stress, achievement motivation and occupation burnout among male nurses. Journal of Avanced Nursing.

Jex, S. (2002). Organizational psychology : a scientist-practitioner approach. New York: Wiley.

Judiciary, K. (2018). Report on the Judiciary Technical Committee Developing the Criminal Procedure Bench Book. Nairobi.

Kampkötter, P., Harbring, C., \& Sliwka, D. (2018). Job rotation and employee performance-evidence from a longitudinal study in the financial services industry. The International Journal of Human Resource Management, 29(10), 1709-1735.

Kebede, S. (2010). Audit of the Status of Police Reforms in Kenya. AMHARA: Unpublished.

Kenya Transparency International. (2016). Kenya Police Service Satisfaction Survey and Needs Analysis ReportA Focus on Kisumu and Nairobi Counties. NAIROBI.

Koustelios, A, Sdrolias, L. \& Aspridis, G. . (2015). Job Satisfaction, Role Conflict and Autonomy of employees in the Greek Banking Organization. Procedia - Social and Behavioual Sciences, 324-333.

Kumar, H. (2010). Practical Guide to Industrial Employment. New Delhi: Universal Law Publishing Co. Pvt. Ltd.

Kumar, P. (1999). Policing Police. Author.

Leigh, E. (2008). Helping people from workless households into work : ninth report of session 2007-08 : report, together with formal minutes, oral and written evidence. London: Stationery Office.

McCourt, W. \& Eldridge, D. (2003). Global Human Resource Management: Managing People in Developing and Transitional Countries. Cheltenham: Edward Elgar.

National Police Service. (2017). The National Police Srvice Standing Orders.

S., Memon, A.A. \& Lodhi, F.A. (2012). Effects of Teachers' transfer on school system. Interdisciplinary Journal of Contemporary Research in Business, 593-617.

Onsumu, W. M. (2014 ). Influence of Teachers' transfer on student academic performance in Public Secondary schools in Kenya. Unpublished University of Nairobi Master of Education pProject.

Ryan, T. (2013). Sample size determination and power. John Wiley \& Sons.

Shtivelband, A. (2014). Applying the theory of Work Adjustment to Recent and non-recent Latino Immigrant Workers. Fort Collins: Unpublished Dissertation In partial fulfillment of the requirements For the Degree of Doctor of Philosophy Colorado State University.

Singh, Y.K. \& Rawat, H. S. (2006). Human Resource Management . New Delhi: APH Publishing Corporation. 
Sisodia, S. \& Das, I. (2013, 10 25). Effect of Job Autonomy Upon Organizationa lCommitmen of Employees at Different Hierarchical Level . Psychological Thought, pp. 2193-7281.

Steijn, B. (2002). HRM and job satisfaction in the Dutch public sector. EGPA-Conference in Potsdam, study group on Public Personnel Policies, (p. 2002 ). DR Rotterdam.

Transparency International Kenya. (2016). Kenya Police Service Satisfaction Survey and Needs Analysis ReportA Focus on Kisumu and Nairobi Counties. Nairobi.

U.S. Department of Justice. (2016). Improving Law Enforcement Resilience. Officer Safety and Wellness Group Meeting Summary. Washington: U.S. Department of Justice. 